\title{
ESTUDO DE CASO: DIAGNÓSTICO DE MANIFESTAÇÕES PATOLÓGICAS EM UMA ESTAÇÃO DE TRATAMENTO DE ESGOTO.
}

\author{
C.M. QUINTÃO*1, C.S.P. RODRIGUES ${ }^{1}$, F.K.CARDOSO ${ }^{1}$, M.C.R. CASTRO ${ }^{1}$, \\ S.V.POMPILHO ${ }^{1}$, D.C.S. GARCIA ${ }^{2}$ \\ *1 Autor de Contacto: cristiano.quintao@copasa.com.br \\ ${ }^{1}$ COPASA - Companhia de Saneamento de Minas Gerais, Belo Horizonte, Brazil. \\ ${ }^{2}$ DEMC- Departamento de Engenharia de Materiais e Construção, UFMG- Universidade Federal de Minas Gerais, \\ Belo Horizonte, Brazil.
}

\begin{abstract}
RESUMO
Este trabalho consiste em um estudo de caso com o objetivo de analisar as manifestações patológicas de uma estrutura de concreto armado degradada em uma Estação de Tratamento de Esgoto (ETE) e sugerir reparos necessários para sua conservação. Realizaram-se vistorias no local, inspeção visual do concreto, descrição das manifestações patológicas e ensaios de caracterização do concreto (carbonatação e teor de sulfatos incorporados). A partir de visitas na ETE, observou-se que as estruturas dos reatores anaeróbios apresentaram várias manifestações patológicas, contudo, as armaduras ainda se encontram passivadas. Além disso, o teor de sulfatos incorporados é considerável apenas na superfície do concreto, reduzindo nas camadas mais internas. Após a análise das manifestações patológicas foram sugeridos reparos necessários para a conservação da estrutura.
\end{abstract}

Palavras clave: Estação de tratamento de Esgoto; Reator UASB; concreto armado; manifestações patológicas em concreto; ataque por sulfatos.

\section{RESUMEN}


Este trabajo consiste en un estudio de caso con el objetivo de analizar las manifestaciones patológicas de una estructura de hormigón armado degradado en una Estación de Tratamiento de las Aguas Residuales (EDAR) y sugerir las reparaciones necesarias para su conservación. Se realizaron inspecciones in situ, inspección visual del hormigón, descripción de las manifestaciones patológicas y ensayos para la caracterización del hormigón (carbonatación y el contenido de sulfatos incorporados). De las visitas a la EDAR, se observó que las estructuras de los reactores anaeróbicos presentaban varias manifestaciones patológicas, sin embargo, los refuerzos aún se encuentran pasivados. Además, el contenido de sulfatos incorporados es alto en la superficie del hormigón, reduciéndose en las capas más internas. Luego de analizar las manifestaciones patológicas, se sugirieron las reparaciones necesarias para la conservación de la estructura.

Palabras clave: Estación de Tratamiento de las Aguas Residuales; Reactor UASB; hormigón armado; manifestaciones patológicas en el hormigón; ataque por sulfatos.

\begin{abstract}
This work is a case study and its aim is to analyze pathological manifestations in degraded reinforced concrete structure in a Wastewater Treatment Plant and suggesting necessary repairs for its conservation. On-site inspections, visual inspection of the concrete, description of the pathological manifestations and tests in concrete (carbonation and sulfate content) were carried out. From visits to the Wastewater Treatment Plant, it was observed that the structures of the anaerobic reactors presented several pathological manifestations, however, the steel are still passivated. In addition, the content of incorporated sulfates is high on the concrete surface, reducing in the innermost layers. After analyzing the pathological manifestations, the necessary repairs for the conservation of the structure were suggested.
\end{abstract}

Keywords: Wastewater treatment Plant, UASB reactor; reinforced concrete; pathological manifestations in concrete; attack by sulfates. 


\section{INTRODUÇÃO}

Os processos de tratamento dos esgotos são formados por uma série de operações unitárias empregadas para a remoção de substâncias indesejáveis, ou para transformação destas substâncias em outras formas aceitáveis. A remoção dos poluentes no tratamento, para adequar o lançamento a uma qualidade desejada ou ao padrão de qualidade estabelecido pela legislação vigente, está associada aos conceitos de nível e eficiência de tratamento (COPASA, 2021).

Os processos de tratamento de esgoto são divididos em sistemas aeróbio e anaeróbio. $\mathrm{O}$ tratamento anaeróbio é efetuado por bactérias que não necessitam de oxigênio para sua respiração, dos quais há três tipos bastante difundidos: tanque séptico, o filtro anaeróbio e o Reator Anaeróbio de Fluxo Ascendente e Manta de Lodo, denominado reator UASB (Upflow Anaerobic Sludge Blanket) (Chan et. al., 2009).

$\mathrm{O}$ reator UASB foi inicialmente desenvolvido e aplicado na Holanda. O processo consiste em um fluxo ascendente de esgotos através de um leito de lodo denso de elevada atividade. Na parte interna, tem-se um dispositivo denominado separador trifásico que tem por objetivo a separação dos gases gerados (biogás), do lodo e do efluente líquido. O lodo é formado de sólidos retidos que constituem a biomassa, permanecendo no reator por tempo suficientemente para que a matéria orgânica seja degradada (Centeno-Mora et. al., 2020). Por causa de sua simplicidade, além de não ser necessária a utilização de material de enchimento e de equipamentos sofisticados, o reator UASB é um dos sistemas mais utilizados para o tratamento de esgotos domésticos.

A maioria dos reatores UASB é construída em concreto armado, material que permite a versatilidade em sua construção, como uma infinidade de formatos, conforme necessidade de projeto, além de ser material considerado de baixo custo e resistente a água (Mazer et al., 2019). As estruturas de concreto aplicadas no tratamento de esgoto apresentam vida útil menor em relação à projetada, por causa da ação de diversos agentes agressivos. A interação dessas construções com esse ambiente agressivo favorece o aparecimento de diversos tipos de manifestações patológicas, que comprometem o desempenho e a integridade física dessas estruturas de concreto (Metha e Monteiro, 2014).

Os agentes agressores que contribuem para essa degradação são: gás carbônico $\left(\mathrm{CO}_{2}\right)$, ácido sulfúrico biogênico $\left(\mathrm{H}_{2} \mathrm{SO}_{4}\right)$ e gás sulfeto de hidrogênio $\left(\mathrm{H}_{2} \mathrm{~S}\right)$. Esses agentes são provenientes da ação de bactérias redutoras de sulfatos que consomem os íons de sulfato presentes no esgoto. No esgoto ainda existem outros componentes que podem ser agressivos às estruturas, como íons sulfatos, cloretos e bicarbonatos. Outros fatores que influenciam a degradação do concreto são: a umidade na região das estruturas expostas ao ar e erosão de elementos abrasivos carreados pelo fluxo de esgoto (Silva et. al., 2016). O entendimento dos fatores e processos responsáveis pela deterioração dessas estruturas permite que sejam tomadas medidas profiláticas, para evitar ou minimizar as manifestações patológicas previstas na etapa de projeto, com a intenção de aumentar a durabilidade dessas estruturas.

As estruturas de concreto, segundo NBR 6.118:2014, devem atender aos requisitos mínimos de qualidade, os quais compreendem segurança à ruptura, desempenho em serviço e capacidade de resistir às influências ambientais previstas e definidas em projeto. A presença de anomalias prejudica inicialmente o desempenho da estrutura, podendo chegar a um estágio tal que comprometa a segurança das estruturas. Portanto, a inspeção minuciosa com a detecção de manifestações patológicas e seu reparo/proteção são atividades fundamentais para atender aos requisitos citados. 


\section{OBJETIVO}

O objetivo desse trabalho é analisar as manifestações patológicas encontradas em uma estrutura de concreto armado degradada em uma Estação de Tratamento de Esgoto (ETE) e sugerir reparos necessários para a sua conservação.

\section{METODOLOGIA}

Para desenvolver o diagnóstico da estrutura de concreto armado na ETE, foram realizadas as seguintes atividades:

- vistoria técnica ao local para levantamento das condições dos reatores UASB;

- inspeção visual, anamnese e identificação do estado atual de conservação da ETE, com a descrição das manifestações patológicas e registro fotográfico;

- realização de ensaios para caracterização do concreto;

- diagnóstico; e

- proposta de recuperação e proteção.

$\mathrm{Na}$ análise e verificação do concreto e elementos estruturais foram utilizadas as prescrições indicadas pelas seguintes normas técnicas:

- ASTM C114-18 - Standart Test Methods for Chemical Analysis of Hydraulic Cement;

- NBR 6.118:2014 - Projeto de estruturas de concreto - Procedimentos.

\subsection{Vistoria técnica ao local para levantamento das condições dos reatores UASB 3.1.1 Descrição da ETE}

A ETE analisada iniciou suas atividades no ano de 2010 e é composta por: tratamento preliminar, extravasor, dois reatores UASB, dois filtros biológicos percoladores, dois decantadores secundários, queimador de gases e desidratação de lodo anaeróbio por oito leitos de secagem, conforme observado na Figura 1. A ETE possui dois módulos de Reatores UASB, cada um com capacidade de tratamento de vazão nominal média de 13,5 1/s, totalizando $27 \mathrm{l} / \mathrm{s}$. Atualmente, a ETE opera com vazão média anual de 40 1/s.

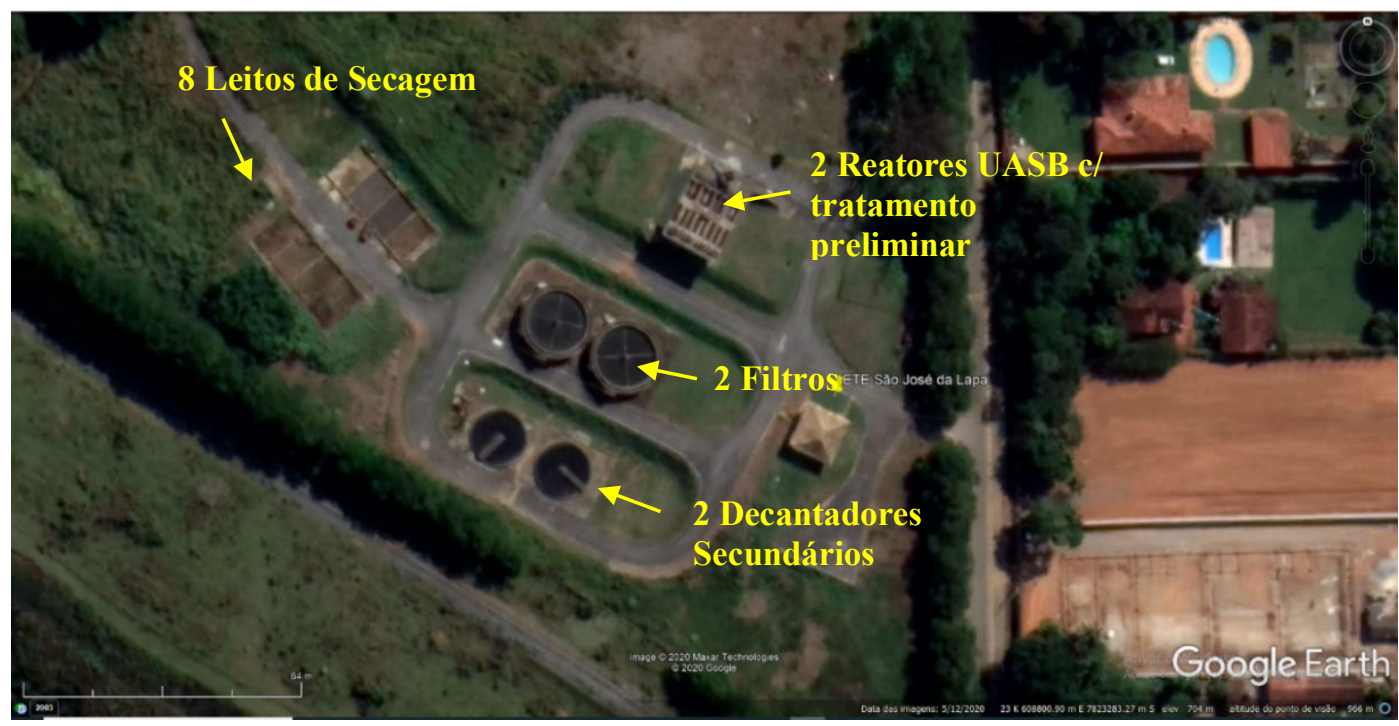

Figura 1 - Imagem de localização da ETE. Fonte: Google Earth. 


\subsubsection{Descrição da Estrutura}

Em 10 anos de operação, houve o desgaste das estruturas de concreto e equipamentos, por causa da elevada agressividade do meio. Isso pode comprometer a durabilidade e integridade estrutural das unidades operacionais e consequentemente, levar a problemas de segurança dos operadores e problemas associados à eficiência do sistema. As estruturas dos reatores UASB da ETE apresentam várias manifestações patológicas.

Em análise de projeto e vistoria ao local, foram obtidas informações sobre as especificações das estruturas dos reatores anaeróbicos. Cada reator foi construído em concreto armado ( $f_{c k}$ de $30 \mathrm{MPa}$ ) e com cobrimento mínimo das armaduras de $3,5 \mathrm{~cm}$ para a parte externa da laje de cobertura e cobrimento mínimo de $4,5 \mathrm{~cm}$ para as demais partes estruturais. Os reatores apresentam geometria retangular tipo apoiado (Figura 2), com largura interna de $6,50 \mathrm{~m}$, comprimento interno de $13,00 \mathrm{~m}$ e altura interna de $5,15 \mathrm{~m}$. As paredes possuem espessura de 30 $\mathrm{cm}$ e a laje de cobertura possui espessura de $15 \mathrm{~cm}$.

Internamente, cada reator possui 4 coifas fabricadas em lona e tubulações de distribuição do esgoto (Figura 3). Cada reator possui oito vãos na laje de cobertura, situados sobre a câmara de decantação, para acesso ao seu interior e realização de limpezas. Esses vãos eram fechados com placas de concreto, porém, devido ao processo de degradação, as placas foram removidas. A estrutura de concreto na região interna, situada sob a lâmina de esgoto, está localizada dentro de um microambiente com Classe de Agressividade IV, agressividade elevada, de acordo com a ABNT NBR 6.118:2014 e Diretrizes para Elaboração de Estudos e Projetos da Companhia de Saneamento.



Figura 2 - Visada Externa dos reatores.

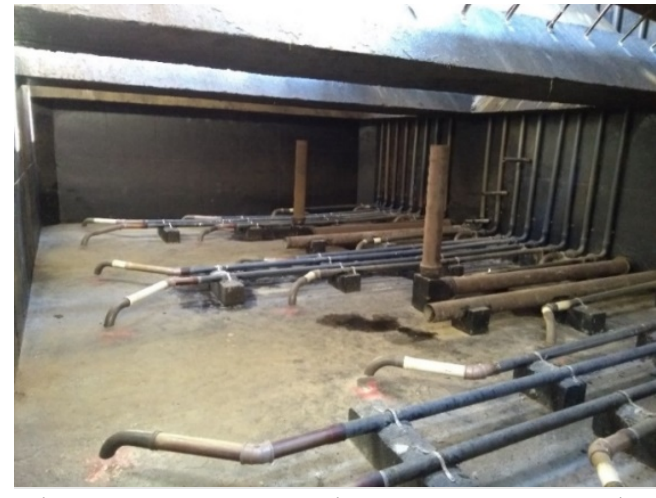

Figura 3 - Vista Interna do compartimento de digestão (região submersa) do reator UASB.

\subsubsection{Inspeção visual, Anamnese e Identificação do Estado Atual de Conservação da ETE}

Para a realização das avaliações e elaboração do diagnóstico estrutural foi realizada inspeção de forma sistêmica e predominantemente sensorial em todas as estruturas, tanto interna como externamente; entrevistas aos operadores para entendimento da história das patologias; e realização de ensaios de campo e laboratoriais, dentro de uma amostragem representativa.

De uma forma geral, observa-se que o concreto exposto ao biogás apresenta claramente um alto nível de desgaste devido a essas intempéries, ou seja, pela utilização da ETE e ausência de sistema de proteção. $\mathrm{O}$ concreto das paredes e lajes degradadas apresenta uma fragilidade tão acentuada, que o material pode ser removido superficialmente com as mãos. Todas as manifestações patológicas foram devidamente identificadas e cadastradas, com o registro das intensidades e severidades em desenhos, que compõem o projeto. 


\subsubsection{Descrição das Manifestações Patológicas Encontradas e Registro Fotográfico}

Devido ao alto grau de deterioração do concreto, foram identificadas várias manifestações patológicas na estrutura do reator e Caixas Distribuidoras de Vazão (CDVs) em estudo. Essas manifestações, muitas vezes, se apresentam em formas associadas e é difícil realizar a distinção de cada tipo isoladamente. As manifestações patológicas estão citadas a seguir:

- fissuras por retração hidráulica e/ou plástica;

- desagregação em toda a superfície de concreto acima do nível de água (Figura 4, 5 e 6), devido aos gases com hidróxido de enxofre gerados no tratamento anaeróbico.

- eflorescências;

- desgaste por erosão da superfície do concreto, com perda de pasta de concreto por ação de fluídos;

- carbonatação (Figura 7): diminuição do pH do concreto, observado com um indicador ácidobase (fenolftaleína);

- corrosão pontual de armaduras;

- fissuras em juntas de concretagem da CDV1, formadas na etapa de obras (Figura 8);

- corrosão do sistema de fixação das tampas de inspeção da região de biogás do reator;

- degradação da tubulação de coleta do efluente tratado, com vazamentos recorrentes, apresentando problemas associados à sua capacidade resistiva.

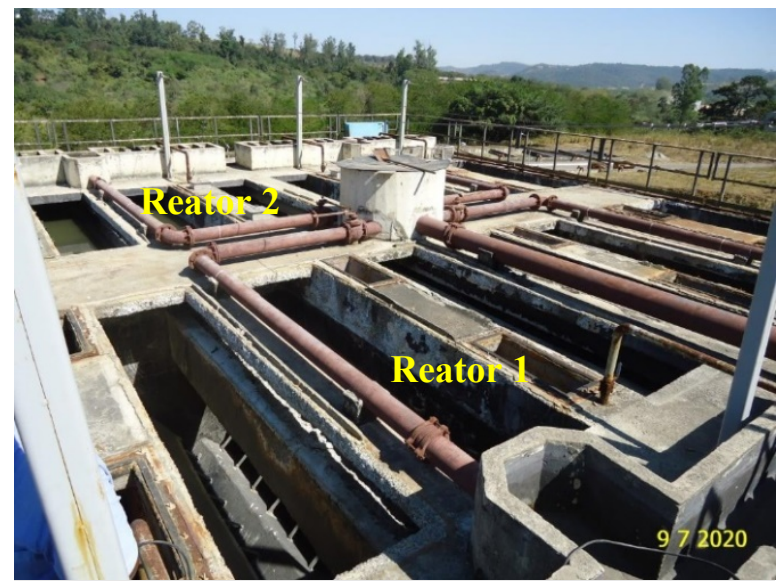

Figura 4 - Vista Geral dos Reatores 1 e 2.

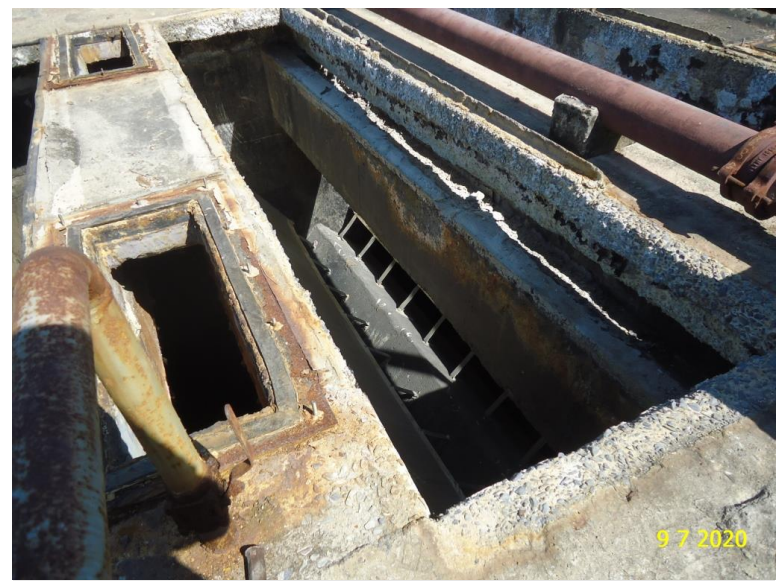

Figura 5 - Detalhe concreto degradado nas aberturas da laje do reator 1 .

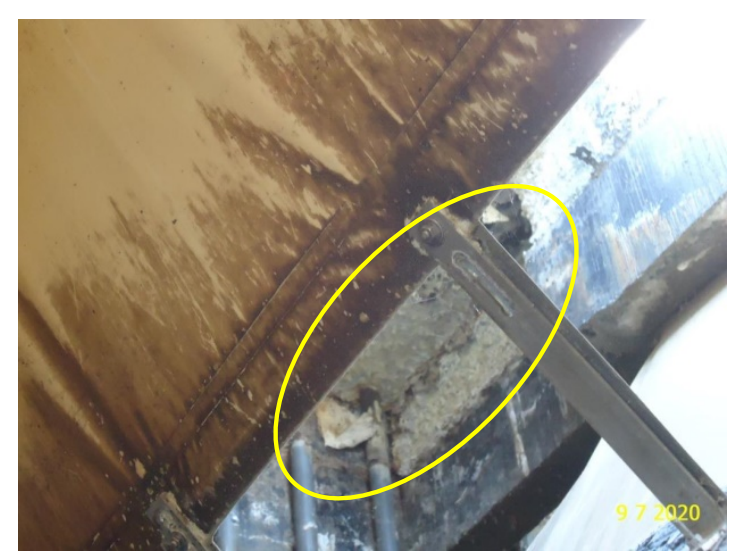

Figura 6 - Vista do concreto degradado sob a laje de cobertura do reator em detalhe, e vista da lona do separador trifásico e sistema de fixação. 


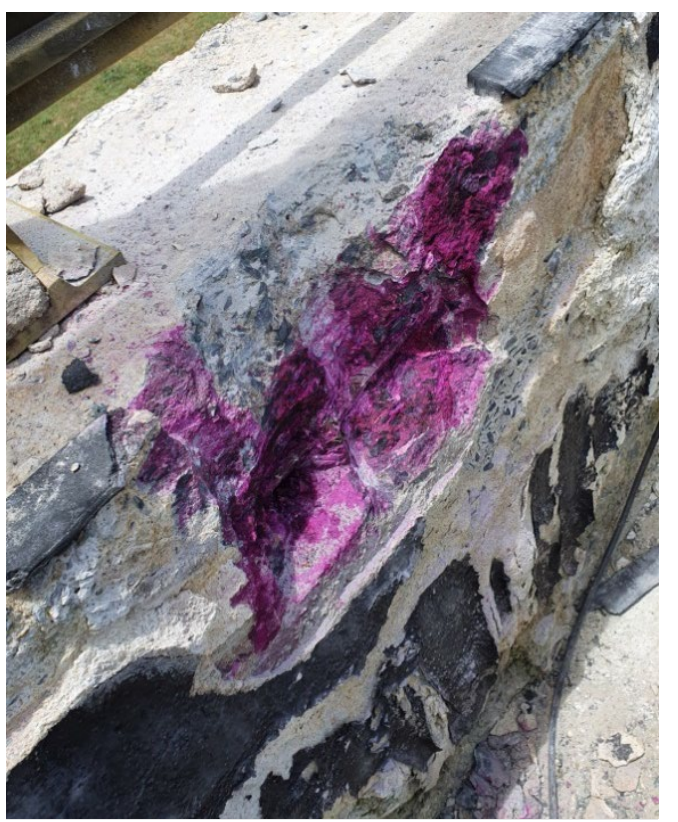

Figura 7 - Parede do canal de efluente tratado, concreto superficial degradado com armadura preservada, envolta por concreto com $\mathrm{pH}$ superior a 8,5 .

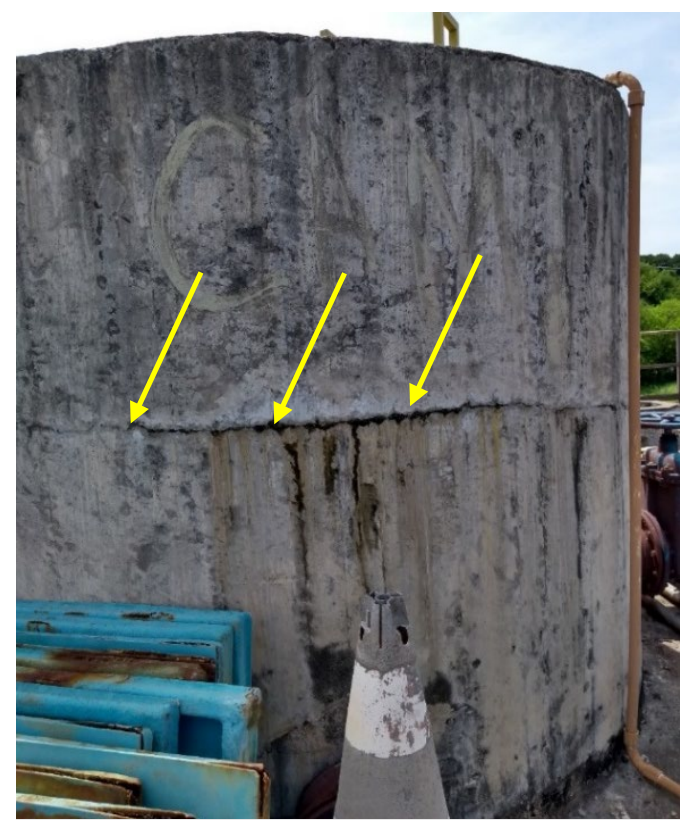

Figura 8 - Fissura ao longo do perímetro da CDV1, com pequenos vazamentos ao longo de seu perímetro.

\subsection{Ensaios Realizados}

Para caracterizar o concreto existente nos reatores e auxiliar na elaboração da proposta de recuperação mais adequada e econômica, foram realizados ensaios de profundidade de carbonatação e de teor de sulfatos incorporados.

\subsubsection{Medição da Profundidade de Carbonatação}

Para determinar a profundidade de carbonatação das estruturas de concreto armado, primeiramente, foi realizada a remoção do concreto desmineralizado (degradado), que possui uma espessura média de $15 \mathrm{~mm}$. A estrutura exposta foi submetida ao ensaio de medição da profundidade da frente de carbonatação através da aspersão de um indicador de pH (fenolftaleína) nas amostras de concreto. Foram retiradas amostras em diferentes profundidades e aspergido fenolftaleína, sendo possível identificar as regiões com cor violeta ( $\mathrm{pH}>8,5$ - mais alcalinas) e regiões incolores (áreas carbonatadas - menos alcalinas).

\subsubsection{Ensaio de Teor de Sulfatos Incorporados}

O processo de degradação do concreto em uma ETE se dá pela interação do íon sulfato com elementos da pasta de cimento, levando a formação de produtos expansivos e perda de coesão. Há também ação de soluções ácidas e ação biológica em função da presença de enxofre, umidade, oxigênio e determinadas bactérias, com dissolução da camada superficial do concreto e formação de sais de cálcio solúveis em água, perda de pasta e exposição dos agregados (Metha e Monteiro, 2014). Assim, o valor máximo recomendado para sulfatos é de 3,5\% (expresso em $\mathrm{SO}_{3}$ sobre a massa de cimento) para concretos de acordo com as normas ABNT NBR 5732, ABNT NBR 11.578, ABNT NBR 5.735, ABNT NBR 5.736 e ABNT NBR 5.733. Além disso, Helene (2003) cita que estruturas de concreto atacadas por sulfatos, com teor de sulfato superior a $5 \%$ na pasta de cimento, devem ser totalmente removidas. 
Para determinar o teor de sulfatos incorporados, foram retiradas amostras em diferentes profundidades da superfície do concreto em contato com o biogás. A primeira amostra foi coletada na superfície degradada do concreto desmineralizado (material friável e sem coesão). As demais amostras foram coletadas a cada $1,5 \mathrm{~cm}$ a partir da região com resistência superficial, totalizando $4,5 \mathrm{~cm}$ de profundidade em diversos pontos da superfície escolhida.

Note que, o teor de sulfatos incorporados foi realizado segundo metodologia definida pela ASTM C114-18. Os ensaios foram realizados através dos métodos Turbidimétrico e Gravimétrico. Cabe elucidar que o teste foi realizado por duas metodologias, pois uma delas, a gravimétrica, é a mais consolidada para ensaios de teor de sulfato em concreto. Como alternativa, apresenta-se a análise por meio do método turbidimetrico, comumente realizado em matrizes de água tratada e residuais. A opção em também realizar a análise turbidimétrica se deu por ser mais fácil de ser realizada (isso pode ser verificado na metodologia), que é mais rápida e consequentemente, mais barata.

- Procedimento Experimental:

Turbidimétrico e Gravimétrico (Fase Inicial):

Os procedimentos iniciais do método Gravimétrico são equivalentes àqueles para a realização do método Turbidimétrico. Aproximadamente $2 \mathrm{~g}$ das amostras de concreto em pó foram utilizadas para a realização dos ensaios (Tabela 1). As porções de $2 \mathrm{~g}$ foram aquecidas a $100^{\circ} \mathrm{C}$ por duas horas, a fim de retirar a umidade. Em seguida, cada amostra foi misturada com $25 \mathrm{ml}$ de água ultrapura e $10 \mathrm{ml}$ de ácido clorídrico, enquanto a solução era misturada com um bastão de vidro. $\mathrm{O}$ teor de íons sulfato neste trabalho foi realizado como uma adaptação da normativa. As soluções foram levadas para uma chapa aquecedora, cobertas por vidros de relógio, até que houvesse um ataque completo do ácido à amostra. Ao final desse processo, adicionou-se $50 \mathrm{ml}$ de água ultrapura quente e deixou-se descansar por 15 minutos. As soluções foram filtradas pelo método do funil de Büchner e papel faixa preta. Ao filtrado foi adicionado água ultrapura até completar $250 \mathrm{ml}$.

Tabela 1 - Nomenclatura adotada para as amostras de concreto.

\begin{tabular}{|c|}
\hline Amostras \\
\hline Amostras Dopagem* n 1 a 4 \\
\hline Amostras Dopagem* 5 a 8 \\
\hline Desmineralizado 1 a 6 \\
\hline 1,5 cm (1 a 3) \\
\hline 3,0 cm (1 a 3) \\
\hline 4,5 cm (1 a 3) \\
\hline
\end{tabular}

*Amostras dopagem: são amostras de um concreto referencial externo à estrutura analisada, utilizadas para realização do processo químico denominado Dopagem Química de Recuperação.

Neste ponto, as amostras desmineralizado 4, 5 e 6, mais pontos " 3 " nas profundidades de 1,5; 3 e $4,5 \mathrm{~cm}$ já estão prontas para serem analisadas pelo método turbidimétrico. As demais amostras seguem para terminar o seu preparo para serem analisadas por gravimetria.

Gravimétrico:

As demais amostras foram aquecidas até ebulição, adicionando-se gota a gota, sob agitação, 10 $\mathrm{ml}$ de cloreto de bário, deixando ferver por cinco minutos. As soluções apresentaram um 
precipitado denominado "Amostras Dopagem", indicativo de sulfato. Os recipientes foram tampados e deixados em descanso por 24 horas. Pela Figura 9 observa-se a diferença de tonalidade das soluções, após as 24 horas, onde as soluções apresentam cor amarelada proporcionalmente aos teores de sulfatos.



Figura 9 - Dissolução das diferentes amostras coletadas.

As amostras foram filtradas em um sistema a vácuo e com papel de $0,45 \mu \mathrm{m}$ e lavandas com água quente até que não fosse identificado mais a presença de cloreto nas águas de lavagem (o que pode ser feito qualitativamente com um indicador misto a base de difenilcarbazona e xilenociano). Posteriormente, o papel de filtro com o precipitado retido foi transferido para um cadinho de porcelana previamente tarado e seco em chapa quente para consumir o carbono, tomando cuidado para o papel não inflamar. O cadinho foi levado a mufla a $600{ }^{\circ} \mathrm{C}$ e calcinado por 1 hora. O percentual de $\mathrm{SO}_{4}$ foi calculado de acordo com Equação (1).

$\mathrm{SO}_{4}=\frac{\text { Massa de } \mathrm{SO}_{4}}{\text { Massa Pesada }} \cdot 100 \%$

\section{RESULTADOS}

\subsection{Medição da Profundidade de Carbonatação}

Foi realizada a remoção do concreto degradado (desmineralizado), sem coesão, até alcançar um substrato com resistência superficial, com uma espessura média de $15 \mathrm{~mm}$ entre camadas, para os pontos analisados (Figura 7). A partir do momento em que se encontrou um substrato resistente, os resultados dos ensaios de carbonatação mostram baixos avanços da frente de carbonatação nas amostras examinadas. A profundidade média de carbonatação foi de $5 \mathrm{~mm}$, comprovando tratarse de elementos estruturais construídos de argamassa de boa qualidade e compactos. É possível afirmar que a frente de carbonatação ainda não atingiu a profundidade das armaduras nos pontos ensaiados. Assim, entende-se que no geral, as armaduras de aço ainda estão passivadas pelo pH alcalino do concreto, com exceção a alguns pontos com baixo cobrimentos da armadura, que apresentaram corrosão pontual, possivelmente provocados por questões construtivas.

\subsection{Ensaio de Teor de Sulfatos Incorporados}

Foram realizados dois métodos de ensaio para determinar o teor de sulfatos incorporados. $\mathrm{O}$ método gravimétrico é o mais utilizado, porém, uma alternativa é o método turbidimétrico, por 
ser mais simples. Tendo isso em mente, a primeira análise realizada foi a comparação das duas metodologias para verificar a viabilidade do método turbidimétrico. Para o método turbidimétrico a recuperação da dopagem foi de 93,1\%, ao passo que a gravimétrica foi de 92,2\% (Tabela 2). Isso sugere que os dois métodos podem ser utilizados, pois, estatisticamente, oferecem resultados de recuperação similares.

Tabela 2 - Estudo de recuperação das metodologias.

\begin{tabular}{|c|c|c|c|c|c|}
\hline MF-0 (média) & MF-1 & MF-2 & Média & DPR (<5\%) & Recuperação \\
\hline 0,01080 & 0,04140 & 0,04260 & 0,04200 & $2,86 \%$ & $93,1 \%$ \\
\hline 0,01635 & 0,04840 & 0,04610 & 0,04725 & $4,87 \%$ & $92,2 \%$ \\
\hline \multicolumn{7}{|c|}{ Observações: } \\
MF - 1: matriz Fortificada 1 (adição do analito) replicata 1 \\
\hline
\end{tabular}

Ainda por meio da análise de "Amostras Dopagem*", é possível verificar que o sulfato já está presente em uma estrutura de concreto sem contato com o efluente. Conforme resultados das Tabela 3, Tabela 4 e Figura 10, observa-se que as amostras de concreto desmineralizado apresentam os maiores teores de sulfato, próximo a 23\%. Devido ao teor de sulfato elevado, é comum a formação de compostos expansivos como a etringita e a formação de novos produtos como sulfato de cálcio hidratado, carbonato de cálcio, dentre outros. Consequentemente, a camada superficial referente ao concreto desmineralizado perdeu sua capacidade aglomerante. Por outro lado, à medida que a profundidade do concreto aumenta, o teor de sulfatos diminui. Note que, o concreto até a profundidade de $1,5 \mathrm{~cm}$ a partir da superfície já apresentou resultados inferiores aos limites fixados por Helene (2003), ou seja, inferior a 5\% na pasta de cimento, indicando que a degradação não está muito profunda, sendo necessária apenas uma remoção superficial do concreto, para sua devida recuperação. Para o cálculo de recuperação foi utilizada a Equação (2).

Tabela 3 - Valores de concentração, massa e porcentagem de sulfato encontrados pelo método turbidimétrico.

\begin{tabular}{|c|c|c|c|c|}
\hline Amostra & Massa pesada (g) & $\begin{array}{c}\text { Concentraç } \\
\text { ão (mg/L) }\end{array}$ & $\begin{array}{c}\text { Massa de } \\
\mathbf{S O}_{\mathbf{4}}(\mathbf{g})\end{array}$ & $\begin{array}{c}\text { \% de } \\
\mathbf{S O}_{4}\end{array}$ \\
\hline MF-0 Amostra Dopagem 3* & 2,0003 & 43,3 & 0,0108 & 0,5412 \\
\hline MF-0 Amostra Dopagem 4* & 2,0008 & 42,8 & 0,0107 & 0,5347 \\
\hline MF-1 Amostra Dopagem 7* & $1,9319+0,06166$ & 165,6 & 0,0414 & 2,0767 \\
\hline MF-2 Amostra Dopagem 8* & $1,9397+0,06056$ & 170,4 & 0,0426 & 2,1298 \\
\hline Desmineralizado 4 & 2,0012 & 2583,0 & 0,6458 & 32,268 \\
\hline Desmineralizado 5 & 2,0014 & 3394,8 & 0,8487 & 42,405 \\
\hline Desmineralizado 6 & 2,003 & 2812,6 & 0,70315 & 35,152 \\
\hline 1,5 cm 3 & 2,0005 & 247,0 & 0,06175 & 3,087 \\
\hline $3,0 \mathrm{~cm} \mathrm{3}$ & $0,4994 *$ & 10,2 & 0,00255 & 0,511 \\
\hline $4,5 \mathrm{~cm} \mathrm{3}$ & 2,0007 & 26,4 & 0,0066 & 0,330 \\
\hline
\end{tabular}

* Menor quantidade de amostra disponível que sobrou depois da realização de duplicata para o método gravimétrico 
Tabela 4 - Valores de concentração, massa e porcentagem de sulfato encontrados pelo método gravimétrico.

\begin{tabular}{|l|l|l|l|l|}
\hline Amostra & Massa pesada (g) & $\begin{array}{l}\text { Massa } \\
\text { Final }\end{array}$ & $\begin{array}{l}\text { Massa de } \\
\mathbf{S O}_{\mathbf{4}}(\mathbf{g})\end{array}$ & \% de SO4 \\
\hline MF-0 Amostra Dopagem 1* & 2,0001 & 0,0521 & 0,0214 & 1,0722 \\
\hline MF-0 Amostra Dopagem 2* & 2,0029 & 0,0274 & 0,0113 & 0,5627 \\
\hline MF-1 Amostra Dopagem $5^{*}$ & $1,9392+0,06056$ & 0,1175 & 0,0484 & 2,4184 \\
\hline MF-2 Amostra Dopagem 6* & $1,9380+0,06025$ & 0,1120 & 0,0461 & 2,3064 \\
\hline Desmineralizado 1 & 2,001 & 1,1189 & 0,4605 & 23,015 \\
\hline Desmineralizado 2 & 2,0005 & 1,1197 & 0,4609 & 23,038 \\
\hline Desmineralizado 3 & 2,0007 & 1,0992 & 0,4524 & 22,614 \\
\hline $1,5 \mathrm{~cm} 1$ & 2,001 & 0,1025 & 0,0422 & 2,108 \\
\hline $1,5 \mathrm{~cm} 2$ & 1,9996 & 0,0553 & 0,0228 & 1,138 \\
\hline $3,0 \mathrm{~cm} 1$ & 2,0023 & 0,0381 & 0,0157 & 0,784 \\
\hline $3,0 \mathrm{~cm} 2$ & 2,001 & 0,0373 & 0,0154 & 0,767 \\
\hline $4,5 \mathrm{~cm} 1$ & 2,0003 & 0,0225 & 0,0093 & 0,463 \\
\hline $4,5 \mathrm{~cm} 2$ & 2,0001 & 0,0183 & 0,0075 & 0,377 \\
\hline
\end{tabular}

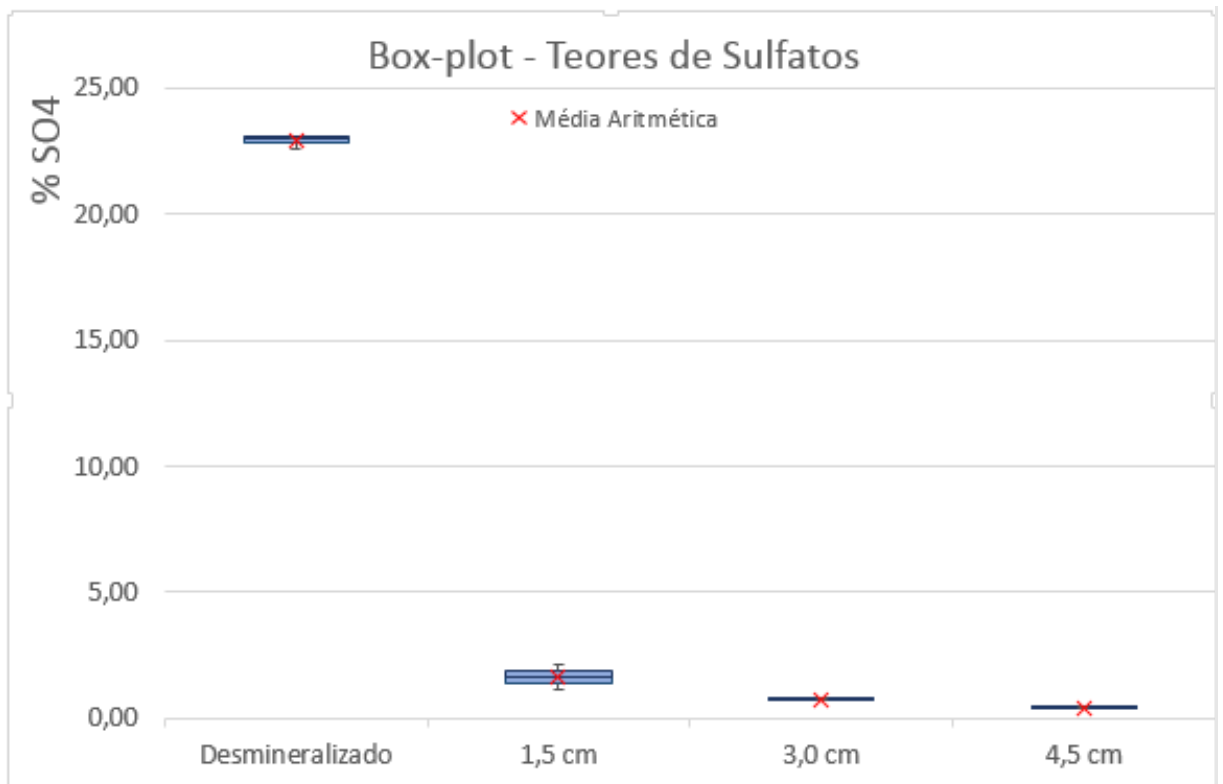

Figura 10 - Gráfico Box-plot dos teores de $\mathrm{SO}_{4}$ (Método Gravimétrico).

Recuperação $=\frac{\text { média- } \mathrm{MF}_{0}}{0,03351 \text { (media da massa de } \mathrm{SO}_{4} \text { adicionada) }}$

\subsection{Considerações / Restrições de Estudos}

Para o diagnóstico da estrutura poderiam ser realizados outros ensaios, que agregariam mais informações, tais como: 
- Ensaio de resistência à compressão do concreto, sendo adotados como premissa a resistência especificada em projeto, para o concreto integro de $30 \mathrm{MPa}$ (não degradado);

- Ensaio de Pacometria, objetivando verificar o posicionamento das armaduras para verificar o cobrimento de concreto e a realização de outros ensaios;

- Ensaio de potencial de corrosão das armaduras, que tem por objetivo determinar a diferença de potencial elétrico entre as armaduras, de modo a estimar a probabilidade de corrosão. Foi realizado apenas inspeção visual das estruturas do reator, que não apresentou danos visíveis significativos às armaduras. Durante etapa de obra, após remoção do concreto degradado deverá ser feita análise das armaduras e realização dos procedimentos de substituição das armaduras, caso apresentem perda de seção do aço.

\section{DIAGNÓSTICO ESTRUTURAL E TERAPIAS RECOMENDADAS}

Através de inspeções de campo foram analisadas as manifestações patológicas nos elementos estruturais do Reator 1 e CDV4. O Reator 2 encontrava-se em operação, não sendo vistoriado, adotado como premissa o mesmo nível de degradação observado do Reator 1. A inspeção visual detalhada, anamnese e ensaios realizados na área interna da estrutura são de fundamental importância para análise global da estrutura do reator.

Dentre as manifestações patológicas observadas na área interna no Reator Anaeróbico, as mais frequentes foram desagregações do concreto e consequentemente sua desmineralização, localizadas internamente na laje de cobertura e nas paredes, acima do Nível d'água. Essas anomalias podem estar relacionadas à etapa de projeto, pois não foi previsto sistema de proteção nos canais de coleta de efluentes tratado e também associados à ausência de manutenção preventiva.

É importante destacar que o ambiente em um reator UASB é altamente agressivo, com a presença de substâncias químicas prejudiciais à estrutura, como o nitrogênio, fósforo, sulfatos e ácido sulfúrico biogênico. Desta forma, as estruturas presentes neste relatório foram classificadas expostas a uma classe de agressividade ambiental IV, de acordo com a ABNT NBR 6118:2014. Não foi possível avaliar o cobrimento das armaduras, para verificar se durante a execução da obra, estavam compatíveis com a norma supramencionada.

$\mathrm{Na}$ laje de cobertura do reator, foram observadas fissuras de retração, geradas possivelmente em função de cura ineficiente do concreto. Além disso, há presença de produtos de corrosão de armaduras no concreto, nas paredes laterais dos reatores, com manchamento das superfícies externas, devido armaduras com baixo cobrimento nas faces superiores das paredes laterais de concreto armado. Nos demais elementos estruturais não foram observados presença de óxidos de ferro, isso indica que não há um estado avançado de corrosão das armaduras. Assim, pode-se considerar que no geral o concreto utilizado na construção da unidade é de boa qualidade e compacidade. A comprovação desse fato se dá através dos valores obtidos dos ensaios de profundidade de carbonatação, que apontou valores baixos nos ensaios, ou seja, um concreto menos permeável.

Em relação à estabilidade do reator, entende-se que as anomalias observadas não comprometam a estabilidade da estrutura, sendo passível de recuperação. Contudo, a evolução das anomalias que atualmente afetam a durabilidade e a funcionalidade das estruturas, possa vir a comprometer a estabilidade do Reator Anaeróbico, caso não seja tratada.

Para recuperação da unidade será necessária a paralisação do reator, limpeza, desinfecção e desmontagem das lonas dos separadores trifásicos. Somente após a recuperação e proteção de um 
reator, será iniciada a recuperação da segunda unidade. Para completar os tratamentos de recuperação propostos, as superfícies internas do reator, situadas acima do N.A deverão receber uma camada de poliuretano elastomérico modificado, para proteção contra os gases, e as superfícies externas da laje de cobertura dos reatores, a aplicação de um sistema impermeabilizante.

Nas aberturas na laje de cobertura, situadas sobre zona de sedimentação do reator, serão instaladas grades em perfis de fibra pultrudados, capazes de resistir ao fluxo dos operadores e resistir quimicamente a agressividade do ambiente.

Com o objetivo de uniformizar as áreas tratadas, melhorando o aspecto visual e protegendo as superfícies externas, deve-se pintar todas as faces laterais externas do reator, utilizando tinta acrílica na cor cinza (tipo Metalatex).

Para a obra de recuperação deverá ser garantida a estabilidade da estrutura, através de um cimbramento adequado.

Assim, conclui-se que pontos mais vulneráveis dessas estruturas devem sempre estar perfeitamente identificados, tanto na fase de projeto quanto de construção, para que seja possível estabelecer, para estes pontos, um programa mais intensivo de inspeções e um sistema de manutenções (Souza e Ripper, 2009). Quanto mais cedo as enfermidades forem detectadas, menor terá sido a perda de desempenho, e mais simples e barato será o tratamento (terapia), que segundo Lei de Sitter (1984), adiar uma terapia significa aumentar os custos numa progressão geométrica de razão igual a cinco (regra dos cincos).

\section{CONCLUSÃO}

O reator UASB é uma tecnologia amplamente utilizada para o tratamento de esgotos em Minas Gerais - Brasil e em outros Estados, de custo construtivo e operacional relativamente baixo se comparado a outras formas de tratamento.

As manifestações patológicas observadas podem ser associadas à etapa de projeto, pois na época, previa-se proteção do concreto apenas para a região de coleta de biogás.

Para definição de terapia adequada para recuperação e proteção estrutural, o diagnóstico é, com certeza, a fase mais importante do processo, que definirá o sucesso ou fracasso dos processos a seres adotados. Para um diagnóstico mais assertivo, muitas vezes se fazem necessário a realização de ensaios, que trarão informações, que nortearão o profissional a definir seu diagnóstico.

É importante ressaltar que para uma melhor comparação entre os dois métodos utilizados para análise dos teores de sulfatos seriam necessários mais dados para ambas as metodologias, o que resultaria em um estudo estatístico mais bem elaborado, visto que o recomendado seriam três valores para cada ponto de análise; sendo que neste estudo, devido as amostras disponíveis, foi utilizado apenas uma amostra para o método turbidimétrico e dois para o gravimétrico. Neste experimento observou-se que o teste por meio do método turbidimetrico pode ser sim uma alternativa mais barata e prática, para determinação de sulfato em concreto, validados pelo alto percentual de recuperação.

Para o reator analisado, foi possível indicar a sua recuperação, pois o ataque agressivo não atingiu as armaduras, estando a estrutura estável, além de ser economicamente viável, comparado aos custos de construção de nova unidade, em substituição à analisada.

Infelizmente muitas obras de recuperação são realizadas por profissionais que não detém conhecimentos especializados em estruturas e materiais, implicando em intervenções que não 
conseguirão tratar as anomalias, e ainda poderão esconder o sintoma, que poderá se manifestar com maior severidade e risco de colapso, além do desperdício de recursos financeiros.

\section{AGRADECIMIENTOS}

Agradecemos à COPASA pelo incentivo na capacitação contínua de seu corpo técnico e à UFMG pela parceria.

\section{REFERENCIAS}

Associação Brasileira de Normas Técnicas. (2014) NBR 6118 - Projeto de estruturas de concreto - Procedimento. Rio de Janeiro, Brasil.

ASTM International. (2018) ASTM C114-18 Standard Test Methods for Chemical Analysis of Hydraulic Cement. www.astm.org

Chan, Y. J., Chong, M. F., Law, C. L., Hassell, D.G. (2009), A review on anaerobic-aerobic treatment of industrial and municipal wastewater. Chemical Engineering Journal. 155:1-18. https://doi.org/10.1016/j.cej.2009.06.041

Centeno-Mora, E., Fonseca, P. R., Andreão, W. L., Brandt, E. M. F., Souza, C. L. S., Chernicharo, C. L. (2020), Mitigation of diffuse $\mathrm{CH}_{4}$ and $\mathrm{H}_{2} \mathrm{~S}$ emissions from the liquid phase of UASB-based sewage treatment plants: challenges, techniques, and perspectives. Environmental Science and Pollution Research. 27:35979-35992.

https://doi.org/10.1007/s11356-020-08644-0

COPASA. https://www.copasa.com.br/wps/portal/internet/esgotamento-sanitario/processos-detratamento, acesso em 05/05/21.

Helene, P. "Manual de Reabilitação de Estruturas de Concreto. Reparo, Reforço e Proteção”. Red Rehabilitar. 718 p. São Paulo, 2003.

Mazer, W., Araújo, J. M., Medeiros, A., Weber, A. M. (2019), Evaluation of sulfate ions in degrading armed concrete structures of a sewage treatment station: case study. Journal of Building Pathology and Rehabilitation. 4(17):1-8.

https://doi.org/10.1007/s41024-019-0056-6

M. S. de A. Silva, J. R. Bertolino, M. H. F. de Medeiros, E. Pereira, J. G. M. Filho (2016). "Deterioração do concreto de reator anaeróbio de lodo fluidizado (RALF) para tratamento de efluentes domésticos" in: $58^{\circ}$ Congresso Brasileiro do concreto, IBRACON - Instituto Brasileiro do Concreto.

Sitter, W. R. (1984). "Costs for service life optimization. The Law of fives" in: International CEB-RILEM workshop on durability of concrete structures. Procedings... Copenhagen: CEBRILEM, p.18-20. 
Souza, V.C.M.; Ripper, T. (2009), “ Patologia, Recuperação e Reforço de Estruturas de Concreto" Editora PINI, São Paulo, 255 p. 